\title{
Hot Water Immersion as a Quarantine Treatment for Large Mangoes: Artificial versus Cage Infestation
}

\author{
K.C. Shellie ${ }^{1}$ and R.L. Mangan \\ U.S.Department of Agriculture, Agricultural Research Service, Kika de la Garza Subtropical Agricultural \\ Research Center, Crop Quality and Fruit Insects Research Unit 2413, E. Business 83, Building 200, \\ Weslaco, TX 78596
}

\begin{abstract}
Additional IndeX words. Mangifera indica, disinfestation, fruit fly, Anastrepha spp., phytosanitary, heat treatment
Abstract. Market demand exists in the United States for fresh mango (Mangifera indica L.) fruit weighing $>700 \mathrm{~g}$, yet fruit of this size cannot be imported for lack of a quarantine treatment against fruit flies (Diptera: Tephritidae). Therefore, the objectives of this research were to evaluate the influence of fruit infestation method on mortality of late third instar, fruit fly larvae after fruit were immersed in hot water, and to generate dose mortality and fruit quality data for mangoes $>700 \mathrm{~g}$. Results suggested that artificial infestation is preferable to cage infestation because artificial infestation eliminates the direct influence of fruit weight loss on the heat dose delivered to the fruit center. Other advantages of artificial over cage infestation include: fruit maturity at treatment is similar to commercial application, mortality of untreated control fruit can be calculated, larval maturity is uniform and observable, and larvae can be placed into the slowest heating part of the fruit. Infesting with $\mathbf{5 0}$ rather than 25 larvae per fruit was preferred because the number of larvae placed into the fruit did not influence mortality and twice as many larvae were evaluated using the same number of fruit. The dose mortality and fruit quality data generated in this research suggest that immersion in water at 46. ${ }^{\circ} \mathrm{C}$ for 110 minutes may provide Probit 9 level quarantine security against Mexican fruit fly (Anastrepha ludens Loew) for mangoes weighing up to $900 \mathrm{~g}$ without adversely affecting fruit market quality.
\end{abstract}

Consumption and demand for mango (Mangifera indica) in the United States has been increasing steadily as consumers become familiar with the taste and good nutritional quality of the fruit. However, commercial production of mango in the United States is limited to small acreages in Florida and outlying islands. A consistent supply of fresh market mango in the United States requires a treatment be available that ensures imported fruit are free of insect pests. Exposure of harvested fruit to heat (hot water or high temperature forced air) is used commercially to meet quarantine requirements against fruit flies (USDA, 1998). Treatment schedules for hot water (T102-a) and hot air (T103-c-1) exist for mango fruit that weigh $<700 \mathrm{~g}$. However, there is market demand in the U.S. for mango fruit weighing $>700 \mathrm{~g}$. Fruit this large cannot currently be imported into the country.

A commodity quarantine treatment provides quarantine security when no individual pest, out of at least 93,613 individuals of the most heat-tolerant life stage, survives exposure to the treatment (Couey and Chew, 1986). Eggs and late third instar larvae are the most heat tolerant life stages of Mexican fruit fly (Anastrepha ludens) (Mangan et al., 1998). When eggs hatch into larvae inside a mango fruit, the larvae burrow through the fruit flesh to feed near the fruit center where the fruit is the ripest. Eggs, located just below the surface of the fruit, cumulatively receive more heat when fruit are immersed in hot water than late third

Received for publication 23 Mar. 2001. Accepted for publication 7 Jan. 2002. This research was conducted under a Trust Fund agreement with Empacadoras de Mango de Exportacion, A.C. We thank Yvette Perez, USDA-APHIS-PPQ, for coordinating activities; Steve Neck, USDA, ARS, for designing and assembling the hot water dip equipment; and Steve Neck, Julie de Leon, and Carlos Solis, USDA, ARS, for assistance conducting the research. Mention of a trademark, proprietary product, or vendor does not constitute a guarantee or warranty of the exclusion of other products or vendors that also may be suitable.

${ }^{1}$ Current address: U.S. Dept. Agr., Agr. Res. Serv., Parma Res. and Ext. Ctr., 29603 U of I Lane, Parma ID 83660. instar larvae located at the fruit center. Therefore, the most difficult life stage to kill using hot water is late third instar larvae. Larval dose mortality data using hot water dips should therefore be generated from infested mangoes that contain late third instar larvae in the center of the fruit when the fruit are immersed in hot water.

The method used to infest the mango has been suspected to affect survival of larvae after fruit are immersed in hot water, however, no published data are available documenting this relationship (Hallman, 2000). Artificial or cage infestation are two methods used commonly to infest fruit for generating dose mortality data. Fruit are artificially infested with larvae by placing a known number of a specific age of larvae into the fruit center by means of an artificial cavity, which is then sealed (Mangan and Ingle, 1994; Mangan et al., 1998; Shellie and Mangan, 2000). Cage infestation involves placing fruit into screened cages that contain an approximate known number of gravid adult flies and allowing the flies to oviposit for 2 to $5 \mathrm{~d}$ directly into the fruit (Mangan and Ingle, 1992; Sharp et al., 1989a). After the fruit are removed from the cage, they are held for a number of days at room temperature to permit egg hatch inside the fruit and development of third instar larvae.

The following research was conducted in two phases. In the first phase, the primary objective was to identify whether the method used to infest mangoes with late third instar Mexican fruit fly larvae influenced the number of pupae recovered from the fruit after the fruit were immersed in hot water. In addition, the influence of fruit maturity on larval survival and conduction of heat into the center of the fruit was also investigated. In the second phase, the principal objective was to generate dose mortality and fruit quality data for mangoes $>700 \mathrm{~g}$. Data generated in the second phase of this research will be used to recommend a duration of hot water dip for confirmatory tests and may ultimately lead to a quarantine treatment against Mexican fruit fly for large mangoes. 


\section{Materials and Methods}

Mangoes were delivered, at weekly or biweekly intervals, from growing locations in Mexico to the international bridge at Pharr, Texas, during April through September 2000. Agricultural Research Service (ARS) personnel, under special permit by USDA, Animal and Plant Health Inspection Service (APHIS), Plant Protection and Quarantine (PPQ), imported the fruit into the United States, and transported the fruit $(\approx 20 \mathrm{~min})$ in an enclosed van to the USDA-ARS Research Laboratory, Weslaco, Texas. The fruit had not been exposed previously to any quarantine treatment, and were transported to the border within $48 \mathrm{~h}$ of harvest.

Fruit were dipped in hot water by placing 20 fruit into a sixsided mesh $\left(2.54 \mathrm{~cm}^{2}\right.$ opening), plastic bin (overall $\mathrm{L} \times \mathrm{W} \times \mathrm{D}, 60$ $\times 40 \times 21 \mathrm{~cm}$ ). Two bins were aligned vertically into a steel-frame carrier and lowered into a 608-L bath using an overhead boom with an electric lift. The temperature of the hot water bath was maintained at $46.1{ }^{\circ} \mathrm{C}$. Timing for dip duration was initiated when the top bin was immersed at least $10 \mathrm{~cm}$ below the surface of the hot water $(\approx 1$ min delay). The hot water dip treatment was terminated when the bottom bin was removed from the hot water bath $(\approx 1$ min delay). Heated fruit were cooled within 2 min after removal from hot water by immersing the bins in an adjacent 608 $\mathrm{L}$ bath that contained water at a temperature no cooler than $21^{\circ} \mathrm{C}$. The fruit were immersed in the ambient temperature bath at least $10 \mathrm{~cm}$ below the surface of the water, and remained immersed until the center temperature of all fruit containing temperature probes was $35^{\circ} \mathrm{C}$ or cooler. The infested mangoes serving as controls for each treatment group were held in a laboratory under ambient conditions while treated fruit were heated and cooled. Upon termination of dipping, treated fruit were held overnight in the laboratory under ambient conditions next to control fruit.

The temperature of the water bath and the center of the mango fruit were recorded at $60 \mathrm{~s}$ intervals throughout heating and cooling. One 36 -guage $(0.13 \mathrm{~mm})$ thermocouple was inserted into each of five fruit per treatment group, just above the surface of the seed, as described by Shellie and Mangan (2000). Three similar sized thermocouples were used to record the temperature of the water at the bottom, middle, and top of the bath. All 36guage, type $\mathrm{T}$ (deviation $0.3{ }^{\circ} \mathrm{C}$ at $100.1{ }^{\circ} \mathrm{C}$ ), plastic tipped thermocouples were connected to a data logger (Datataker DT500 Series 2; Data Electronics, Carrolton, Texas), and transferred to an electronic spreadsheet for analysis. Average fruit center temperature during heating and cooling was calculated for the fruit that contained temperature probes in each dip replication. Temperature data were displayed graphically using Sigmaplot (SPSS, Inc. Chicago, Ill.).

Larvae were removed from treated and control fruit the morning after treated fruit were heated and cooled. After larvae were removed from the fruit and counted, the mango fruit pulp was discarded. The larvae removed from the fruit were stored at $23{ }^{\circ} \mathrm{C}$ for $7 \mathrm{~d}$ in vermiculite inside sealed, air ventilated plastic containers. After $7 \mathrm{~d}$ of storage, the vermiculite was sifted, and the actual number of pupae in each plastic container was recorded. All pupae recovered from treated and control fruit were considered survivors. Eclosion was not evaluated.

INFESTATION METHOD, PHASE 1. Mango fruit were artificially or cage infested with late third instar larvae of the West Indian fruit fly (Anastrepha obliqua Macquart). The West Indian fruit fly was utilized because published data suggested West Indian fruit fly was more tolerant to heat than the Mexican fruit fly (Sharp et al., 1989a) or the Caribbean fruit fly (Anastrepha suspensa Loew) (Sharp et al., 1989b). All infested fruit were immersed in $46.1^{\circ} \mathrm{C}$ water for $70 \mathrm{~min}$ and cooled immediately in water as described previously. Twenty mango fruit weighing $\approx 790 \mathrm{~g}$ each and of market quality similar to mangoes commercially hot water dipped, i.e., mature green and free of visible external defects, were cage infested for $48 \mathrm{~h}$ using the method of Sharp et al. (1989a, 1989b) and Mangan and Ingle (1992). However, the infested fruit were held for 18 instead of $5 \mathrm{~d}$ after cage infestation in order to obtain late third instar larvae. Fruit of similar market quality as mangoes commercially hot water dipped, i.e., mature green and free of visible external defects, were also artificially infested with either 25 or 50 late third instar West Indian fruit fly larvae, $2 \mathrm{~h}$ before hot water dipping using the method of Mangan and Ingle (1994). The third instars used to artificially infest the fruit were removed from rearing medium at $9 \mathrm{~d}$ of age.

Cage and artificially infested fruit were placed in separate plastic treatment bins and the bins were immersed for $70 \mathrm{~min}$ in the same water bath. Each infestation method was replicated twice with 20 fruit per replication. Twenty additional fruit in each replication were cage or artificially infested but not immersed in hot water to serve as controls. Larvae recovered from infested treated and control fruit were placed on vermiculite in individually numbered plastic containers and evaluated for pupae as described previously. The number of pupae recovered from each treated fruit was analyzed by analysis of variance (ANOVA) with infestation method and replication as main effects and infestation method by replication as the error term.

LARVAL SURVIVAL AND FRUIT MATURITY, PHASE 1. The influence of fruit maturity on larval survival was assessed by infesting 13 , similarly sized fruit of mature green or postcolorbreak maturity, for $48 \mathrm{~h}$ in a cage containing West Indian fruit fly (as described previously). The fruit were held after cage infestation for $18 \mathrm{~d}$, and the number of pupae recovered was recorded as described previously. The 13 fruit in each maturity group were considered replications.

HEAT CONDUCTION AND FRUIT MATURITy, PHASE 1. The rate at which heat conducts through mature green vs. postcolorbreak fruit was measured by monitoring the center temperature of 12 mature green mangoes weighing $732 \pm 47 \mathrm{~g}$ and 12 postcolorbreak mangoes weighing $770 \pm 89 \mathrm{~g}$ during $70 \mathrm{~min}$ of immersion in hot water and cooling as described previously. The 12 fruit in each maturity group were considered replications.

DOSE MORTALITY, PHASE 2. Dose mortality data were generated using mature green mangoes, weighing $\approx 847 \pm 78 \mathrm{~g}$, that had similar market quality as mangoes dipped commercially in hot water. In preliminary tests, we observed that third instar larvae of our lab-reared strain of West Indian fruit fly were less heat tolerant than our lab-reared strain of Mexican fruit fly larvae. We therefore decided to artificially infest (as described previously) fruit with 50 late, third instar Mexican instead of West Indian fruit flies. The late third instar Mexican fruit fly larvae were obtained from a colony founded in 2000 with material from Mexico, and maintained at the USDA-ARS laboratory in Weslaco, Texas. Larvae were reared on a standard fruit fly diet of rehydrated carrot (Daucus carota L.) powder and torula yeast (Candida utlis Henneberg) (Spishakoff and Hernandez Davila, 1968) in a room maintained at $26.7 \pm 2{ }^{\circ} \mathrm{C}$. The third instars used in this research were removed from the rearing medium at $9 \mathrm{~d}$ of age. The infested fruit were immersed for $70,75,80,90,100,105,110,115$, or 120 min in water at $46.1{ }^{\circ} \mathrm{C}$, and cooled immediately in water, as described previously. Treatment durations were replicated until 
Table 1. Average number of West Indian fruit fly pupae recovered from infested mangoes after the fruit were immersed in water at $46.1{ }^{\circ} \mathrm{C}$ for 70 min and cooled immediately in water at a temperature no cooler than $21^{\circ} \mathrm{C}$. Before treatment, mangoes were infested artificially with 25 or 50 late third instar larvae or for $48 \mathrm{~h}$ in a cage containing adult flies and held at $25^{\circ} \mathrm{C}$ for $18 \mathrm{~d}$.

\begin{tabular}{|c|c|c|c|c|}
\hline \multirow[b]{2}{*}{ Infestation method } & \multirow[b]{2}{*}{ Fruit (no.) } & \multicolumn{2}{|c|}{$70 \mathrm{~min}, 46.1^{\circ} \mathrm{C}$ water } & \multirow{2}{*}{$\begin{array}{c}\text { Controls } \\
\text { Pupae/fruit (no.) }\end{array}$} \\
\hline & & Weight $\operatorname{loss}^{\mathrm{z}}(\%)$ & Pupae/fruit (no.) & \\
\hline$\overline{\text { Artificial, } 25 \text { larvae }}$ & 40 & 0 & $0.6 \mathrm{a}^{\mathrm{y}}$ & 16.5 \\
\hline Artificial, 50 larvae & 40 & 0 & $1.4 \mathrm{a}$ & 37.0 \\
\hline $48 \mathrm{~h}$ inside cage & 39 & 30 & $1.3 \mathrm{a}$ & 3.1 \\
\hline
\end{tabular}

${ }^{\mathrm{z}}[$ (Preinfestation weight - pretreatment weight $) /$ preinfestation weight $] \times 100$.

${ }^{y}$ Mean separation within column by LSD, $P \leq 0.05$.

at least 2000 larvae were treated at each time interval. For each replication, 10 additional fruit were also artificially infested with 50 larvae and not immersed in hot water to serve as infested controls.

Larvae recovered from 10 of the 20 hot water dipped fruit were bulked together into one plastic container with vermiculite. Two plastic containers, each holding $\approx 500$ live or dead larvae, were used for each group of 20 infested fruit. Larvae recovered from the 10 control fruit for each treatment group were also bulked into a single plastic container. The number of pupae recovered from each container was evaluated as described previously. Percentage mortality per container was calculated by subtracting the number of pupae recovered per container from 500, dividing the difference by 500 , and multiplying by 100 . Percentage mortality per treatment duration was calculated as the sum of mortality per container divided by the number of containers per treatment group. Standard deviation for percentage mortality was calculated from mortality per container values.

Fruit QUality, PHASE 2. When fruit were dipped for $110 \mathrm{~min}$, five noninfested fruit, of similar weight and maturity, were hot water dipped along with infested fruit and used to evaluate fruit quality attributes. Five additional, noninfested fruit were also allocated as controls for fruit quality attributes. Fruit quality controls were handled during the dipping treatment similar to infested fruit controls. Mango fruit quality attributes were evaluated after the fruit were stored for $14 \mathrm{~d}$ in air at $13{ }^{\circ} \mathrm{C}$, and five additional days in air at $23{ }^{\circ} \mathrm{C}$. Treated and control fruit were numbered on the stem end before dipping and three $2-\mathrm{cm}$ diameter circles were drawn along the equatorial surface. The color of the mango rind inside the circles was measured with a chromameter (model CR-200; Minolta Corp., Ramsey, N.J.) prior to dipping and after storage, and recorded as the average of three readings in the $\mathrm{L}^{*}, \mathrm{C}^{*}$, $\mathrm{h}^{\circ}$ color mode ( $\mathrm{L}^{*}$, lightness; $\mathrm{C}^{*}$, chroma; and $\mathrm{h}^{\circ}$, hue angle) under standard illuminant C (Little, 1975). The color of the mango pulp was measured after storage using the same method. Fruit external appearance, decay, and internal disorders were rated subjectively after storage using a five-point scale with $0=0 \%, 1=15 \%, 2=50 \%, 3=$ $85 \%$, and $4=100 \%$ of the fruit affected. An untrained preference panel rated the flavor of treated and control fruit after storage using a $9.5-\mathrm{cm}$ line scale anchored with the terms "dislike extremely" at the left end and "like extremely" on the right (Shellie and Mangan, 1994). Flesh firmness after storage was measured in $\mathrm{N}$ with a drill press mounted force gauge (Ametek, Largo, Fla.) having a $6 \mathrm{~mm}$ diameter, veehead probe. Percentage fruit weight loss was calculated by subtracting poststorage weight from pretreatment weight, dividing by pretreatment weight and multiplying by 100 . The magnitude of change in rind color during storage was measured by obtaining the absolute value of the difference between pre and poststorage values for $\mathrm{L}^{*}, \mathrm{C}^{*}$, and $\mathrm{h}^{\circ}$. Quality data were subjected to ANOVA with hot water dip duration as the main effect.

\section{Results and Discussion.}

INFESTATION METHOD, PHASE 1. A similar number of pupae were recovered from cage infested as from artificially infested mangoes after hot water immersion (Table 1). Nontreatment related mortality of artificially infested control fruit larvae was $36 \%$ and $26 \%$ when fruit were infested with 25 or 50 larvae, respectively. However, nontreatment related mortality of cageinfested control fruit could not be calculated because initial infestation number was impossible to determine.

Cage infested mangoes lost $\approx 30 \%$ of their preinfested fruit weight during the required $18 \mathrm{~d}$ days of storage for obtaining third instar larvae (Table 1). This $30 \%$ loss in weight resulted in the cage-infested fruit receiving a more severe heat dose than artificially infested fruit (Fig. 1). Fruit center temperature after $60 \mathrm{~min}$ of immersion, when the center temperature of cage-infested fruit

Fig. 1. Center temperature of mango fruit artificially (closed symbols) or cage infested (open symbol) during immersion for $70 \mathrm{~min}$ in water at $46.1^{\circ} \mathrm{C}$, and cooling in water at $21^{\circ} \mathrm{C}$. SE bars are based on average of three replications with 20 fruit per replication.

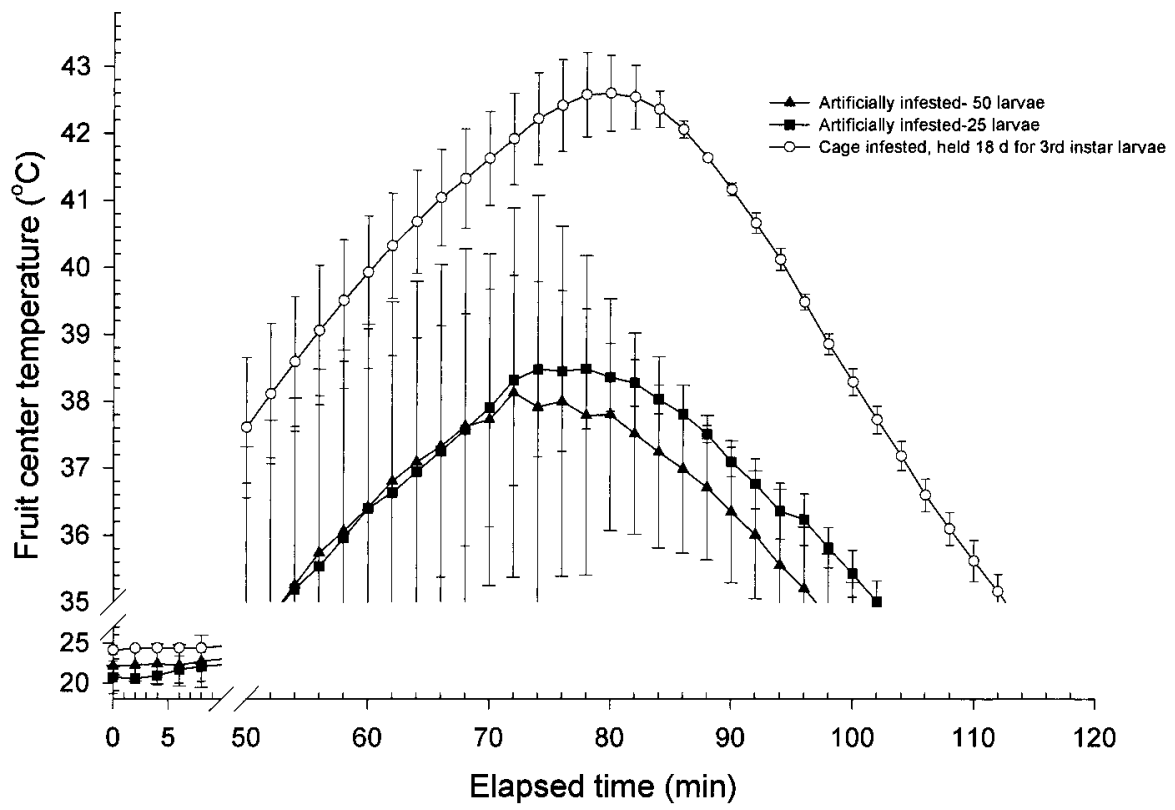




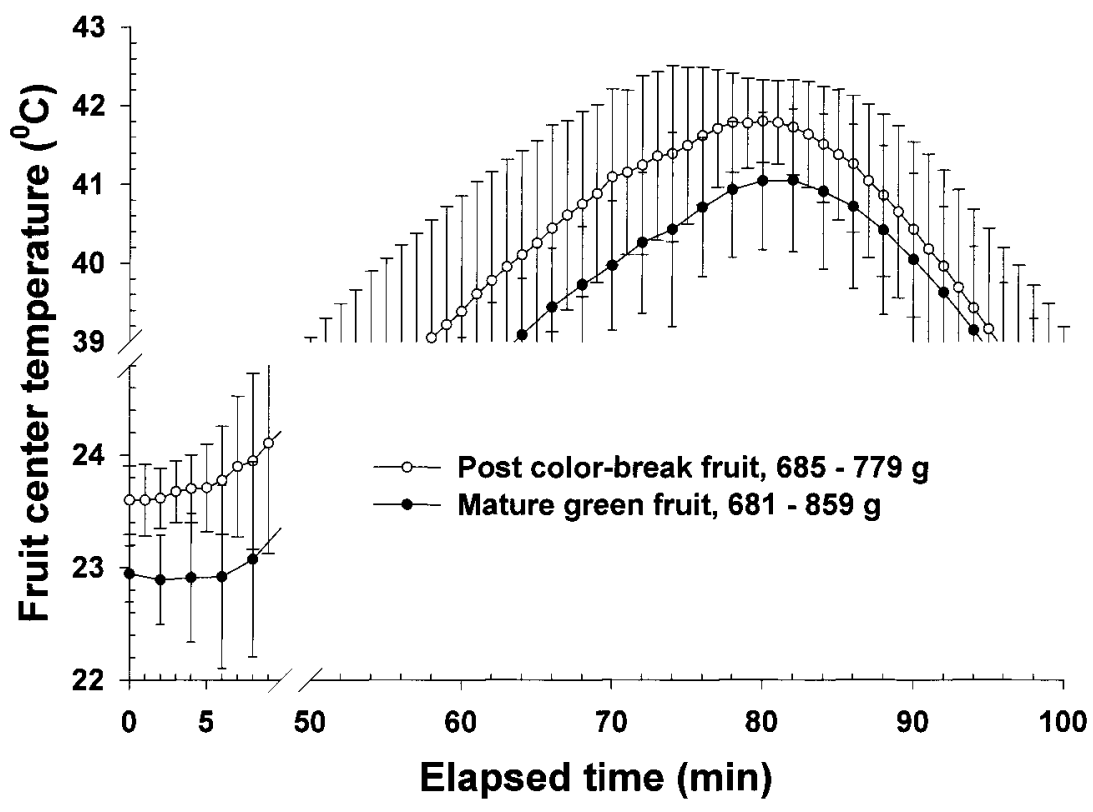

Fig. 2. Fruit center temperature of postcolorbreak (open circles) and mature green (closed circles) mangoes during immersion for $70 \mathrm{~min}$ in water at $46.1^{\circ} \mathrm{C}$ and cooling in water at $21^{\circ} \mathrm{C}$. The range in weight of individual postcolorbreak fruit was 685 to $779 \mathrm{~g}$ and 681 to $859 \mathrm{~g}$ for mature green fruit. $\mathrm{sE}$ bars $(\mathrm{n}=12)$ are based on individual fruit.

Table 2. Average number of West Indian fruit fly pupae recovered from 13 mature green or postcolorbreak mangoes after cage infestation for $48 \mathrm{~h}$ and $18 \mathrm{~d}$ of holding at $25^{\circ} \mathrm{C}$.

\begin{tabular}{lcc}
\hline \hline Fruit maturity at infestation & Fruit (no.) & Pupae (no.) \\
\hline Mature green & 13 & $283.6 \mathrm{a}^{\mathrm{z}}$ \\
Postcolorbreak & 13 & $524.2 \mathrm{~b}$
\end{tabular}

${ }^{\mathrm{z}}$ Mean separation by LSD (208), $P=0.03$.

reached $40^{\circ} \mathrm{C}$, was significantly hotter in cage-infested mangoes than artificially infested mangoes. The center temperature of artificially infested fruit never reached $40^{\circ} \mathrm{C}$ during the $70 \mathrm{~min}$ of hot water immersion. Mangan et al. (1998) estimated that third instar larvae require at least $37 \mathrm{~min}$ of exposure to $43^{\circ} \mathrm{C}$ to kill $50 \%$ of larvae. The large number of survivors recovered from the most severe heat dose in this research supports this estimate. The 30\% fruit weight loss observed during holding after cage infestation suggests that mortality differences between cage and artificial infestation would become apparent as heat dose severity increased.
HEAT CONDUCTION AND FRUIT MATURITY, PHASE 1. Mature-green and postcolorbreak mangoes of similar weight had similar rates of heating and cooling at the fruit center (Fig. 2). The similar rate of heating and cooling for mature-green and postcolorbreak mangoes verifies that weight loss during the holding period after cage infestation, rather than fruit ripening per se, was responsible for the faster heating rate of cage-infested fruit (Fig. 1). Controlling the storage environment during the holding period by refrigeration or controlled atmosphere could reduce fruit weight loss during the holding period after cage infestation, but it would also delay or prevent larval development in the fruit. These results demonstrate that weight loss of cage-infested fruit during holding has a direct effect on the rate at which heat is conducted to the fruit center. To compensate for inevitable fruit weight loss during holding after cage infestation, we suggest cage infesting fruit weighing 30\% heavier than the fruit size being targeted for hot water treatment.

Larval survival and fruit Maturity, PHaSe 1. Pupae were recovered from mature-green as well as from postcolorbreak mangoes (Table 2). However, $\approx 46 \%$ (240) more pupae were recovered from postcolorbreak mangoes than from mature-green mangoes. These results suggest that while harvested mango should be considered a host for the West Indian fruit fly regardless of fruit maturity, postcolorbreak fruit are a preferred host over mature green fruit.

DOSE MORTALITY AND FRUIT QUALITY, PHASE 2. No survivors were recovered out of 4000 treated larvae when mangoes weighing $\approx 900 \mathrm{~g}$ were immersed in water at $46.1^{\circ} \mathrm{C}$ for $110 \mathrm{~min}$ (Table 3 ). Survivors were recovered when fruit were immersed for $<110$ min. Average larval mortality for control fruit was $4.6 \% \pm 1.8 \%$. Fruit immersed for 110,115 , or 120 min reached a similar maximum fruit center temperature $\left(43^{\circ} \mathrm{C}\right)$ as fruit immersed for $100 \mathrm{~min}$ (Fig. 3). However, more potentially lethal heat accumulated at the fruit center as immersion time was extended.

Some differences in quality attributes of mangoes immersed in hot water for 110 min were apparent after fruit were cold stored and ripened (Table 4). Mangoes immersed for $110 \mathrm{~min}$ in hot water lost $\approx 0.6 \%$ less weight during storage and ripening than control fruit. These results suggest that treated fruit absorb water during immersion, and may have implications for food safety.

Table 3. Average fruit weight and percentage mortality of late third instar Mexican fruit fly larvae recovered from artificially infested mangoes after immersion in $46.1^{\circ} \mathrm{C}$ water for $70,75,80,90,100,105,110,115$, or $120 \mathrm{~min}$. Mangoes were cooled after heating in water no cooler than $21^{\circ} \mathrm{C}$.

\begin{tabular}{|c|c|c|c|c|c|}
\hline Dip time $(\min )$ & \multicolumn{3}{|c|}{ Hot water dip } & \multicolumn{2}{|c|}{ Controls } \\
\hline$\overline{70}$ & $16.9(7.4)$ & $820.8(16.5)$ & 2000 & $2.8(0.0)$ & 500 \\
\hline 80 & $75.2(17.2)$ & $863.3(44.8)$ & 3000 & $6.4(4.2)$ & 1000 \\
\hline 90 & $71.9(26.2)$ & $891.1(62.5)$ & 4000 & $1.4(0.8)$ & 1000 \\
\hline 100 & $99.4(1.0)$ & $832.3(34.6)$ & 4000 & $4.0(1.4)$ & 1000 \\
\hline 115 & $100(0.0)$ & $909.2(42.1)$ & 2000 & $4.0(0.0)$ & 500 \\
\hline 120 & $100(0.0)$ & $914.0(84.7)$ & 2000 & $5.6(0.0)$ & 500 \\
\hline
\end{tabular}

${ }^{\mathrm{z}}$ Average percentage mortality calculated as the sum of [(500 - no. of pupae per container)/500] $\times 100$ divided by the total number of containers. Number in parentheses is the SD of percentage mortality among containers. 


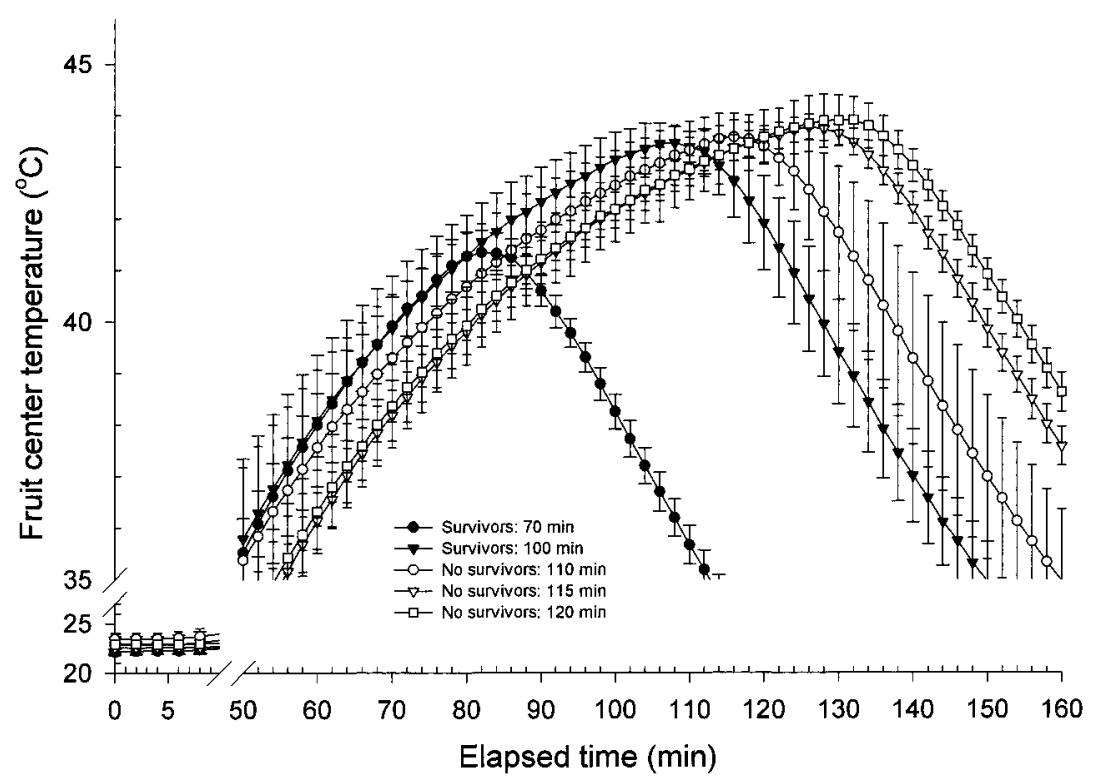

nontreatment related mortality of control fruit can be calculated, maturity of larvae is known and uniform, and larvae can be placed in the most difficult to heat location. Since larval mortality was shown to be similar for fruit artificially infested with 25 or 50 larvae, artificial infestation with 50 larvae is the preferred method because it enables evaluation of a greater number of larvae utilizing fewer fruit.

\section{Literature Cited}

Couey, H. and V. Chew. 1986. Confidence limits and sample size in quarantine research. J. Econ. Entomol. 79:887-890.

Hallman, G.J. 2000. Factors affecting quarantine heat treatment efficacy. Postharvest Biol. and Technol. 21:95-101.

Little, A.C. 1975. Off on a tangent. J. Food Sci. 40:410 411.

Mangan, R.L. and S.J. Ingle. 1992. Forced hot-air quar-

Fig. 3. Mango fruit center temperature during immersion for 70 or $100 \mathrm{~min}$ (closed symbols) when survivors were recovered from the fruit, or for 110,115 , or 120 $\min$ (open symbols) when no survivors were recovered from the fruit. Fruit were immersed in water at $46.1{ }^{\circ} \mathrm{C}$ and cooled in water at $21^{\circ} \mathrm{C}$. SE bars $(\mathrm{n}=20)$ are based on individual fruit.

The rind color of treated and control fruit changed after storage, with $\mathrm{L}$ values increasing (becoming lighter), chroma increasing (richer color), and hue angle decreasing (becoming less green). However, changes in rind color after storage were of greater magnitude when mangoes were hot water dipped (Table 4). The greater magnitude of change in rind color of hot water dipped fruit compared to control fruit suggests that dipping in hot water accelerates fruit ripening. No other changes in measured quality attributes were significant (data not presented), suggesting that acceleration of ripening was of small magnitude.

The dose mortality and fruit quality data generated in this research suggest that immersion in water at $46.1^{\circ} \mathrm{C}$ for $110 \mathrm{~min}$ may provide quarantine security against Mexican fruit fly for mangoes weighing up to $900 \mathrm{~g}$ without adversely affecting fruit market quality. Results from this research suggest a number of advantages of artificial versus cage infestation in evaluating the mortality of late third instar larvae. When heat is the method of treatment, artificial infestation eliminates the direct influence of fruit weight loss on the heat dose delivered to the fruit center. Other advantages of artificial over cage infestation include: fruit maturity at treatment is similar to commercial application, antine treatment for mangoes infested with West Indian fruit fly (Diptera: Tephritidae). J. Econ. Entomol. 85:1859-1864.

Mangan, R.L. and S.J. Ingle. 1994. Forced hot air quarantine treatment for grapefruit infested with Mexican fruit fly. J. Econ. Entomol. 87:1574-1579.

Mangan, R.L., K.C. Shellie, S.J. Ingle, and M.J. Firko. 1998. High temperature forced-air treatments with fixed time and temperature for 'Dancy' tangerines, 'Valencia'oranges, and 'Rio Star' grapefruit. J. Econ. Entomol. 91:933-939.

Sharp, J.L., M.T. Ouye, S.J. Ingle, and W.G. Hart. 1989a. Hot-water quarantine treatment for mangoes from Mexico infested with Mexican fruit fly and West Indian fruit fly (Diptera: Tephritidae). J. Econ. Entomol. 82:1657-1662.

Sharp, J.L., M.G. Ouye, R. Thalman, W. Hart, S. Ingle, and V. Chew. 1989b. Submersion of 'Francis' mango in hot water as a quarantine treatment for the West Indian fruit fly and the Caribbean fruit fly (Diptera: Tephritidae). J. Econ. Entomol. 81:1431-1436.

Shellie, K.C. and R.L. Mangan. 1994. Postharvest quality of 'Valencia' orange after exposure to hot, moist, forced air for fruit fly disinfestations. HortScience 29:1524-1527.

Shellie, K.C. and R.L. Mangan. 2000. Postharvest disinfestation heat treatments: Response of fruit and fruit fly larvae to different heating media. Postharvest Biol. and Technol. 21:51-60.

Spishakoff, L.M. and J.G. Hernandez Davila. 1968. Dried torula yeast as a substitute for brewer's yeast in the larval rearing medium for the Mexican fruit fly. J. Econ. Entomol. 61:859-860.

U.S. Department of Agriculture. 1998. Plant protection and quarantine treatment manual. U.S. Dept. Agr., Animal and Plant Health Inspection Serv., Riverdale, Md.

Table 4. Quality of mature green mangoes weighing $726 \mathrm{~g}$ after immersion in water at $46.1^{\circ} \mathrm{C}$ for 110 min and immediate cooling in water. Quality attributes were measured after fruit were stored in air at $13{ }^{\circ} \mathrm{C}$ for $14 \mathrm{~d}$ and stored $5 \mathrm{~d}$ in air at $23{ }^{\circ} \mathrm{C}$.

\begin{tabular}{|c|c|c|c|c|c|}
\hline \multirow{2}{*}{$\begin{array}{l}\text { Dip } \\
(\min )\end{array}$} & \multirow{2}{*}{$\begin{array}{c}\text { Weight loss }{ }^{\mathrm{z}} \\
(\%)\end{array}$} & \multicolumn{3}{|c|}{ Change in fruit exterior color ${ }^{y}$} & \multirow{2}{*}{$\begin{array}{c}\text { Flavor }^{\mathrm{x}} \\
(\mathrm{cm})\end{array}$} \\
\hline & & $\mathrm{L}^{*}$ & Chroma & Hue & \\
\hline 110 & $4.7 \mathrm{a}^{\mathrm{w}}$ & $6.2 \mathrm{a}$ & $12.2 \mathrm{a}$ & $25.4 \mathrm{a}$ & $5.71 \mathrm{a}$ \\
\hline 0 & $5.3 \mathrm{~b}$ & $1.3 \mathrm{~b}$ & $5.9 \mathrm{a}$ & $17.3 \mathrm{a}$ & $5.73 \mathrm{a}$ \\
\hline
\end{tabular}

${ }^{\mathrm{Z}}[$ (Pretreatment fruit weight - poststorage fruit weight $) /$ pretreatment fruit weight $] \times 100$.

${ }^{y}$ Change for $\mathrm{L}^{*}$ (lightness) and chroma calculated as the difference between poststorage and pretreatment values. Hue change calculated as the difference between pretreatment and poststorage values.

"Preference panel ratings based on a 9.5-cm line scale anchored with the terms "dislike extremely" at the left and "like extremely" on the right.

${ }^{\mathrm{w}}$ Mean separation $(\mathrm{n}=25)$ within columns by LSD, $P \leq 0.05$. 